\title{
Bargaining Power and Efficiency in Insurance Contracts
}

\author{
John Quiggin ${ }^{\mathrm{a}}$ and Robert G. Chambers ${ }^{\mathrm{b}}$ \\ ${ }^{a}$ School of Economics, University of Queensland, Brisbane, Queensland 4072, Australia. \\ E-mail: j.quiggin@uq.edu.au \\ ${ }^{\mathrm{b}}$ Department of Agricultural and Resource Economics, University of Maryland, College Park, \\ Maryland 20742, USA. \\ E-mail: rchambers@arec.umd.edu
}

Insurance contracts are frequently modelled as principal-agent relationships. The purpose of this paper is to examine the interaction between differential bargaining power and the efficiency of insurance contracts. The analysis is undertaken in a framework of state-contingent production, which allows us to consider, as separate choices, the level of effort committed by the client and the riskiness of the equilibrium state-contingent production vector. Our central result is that, in the presence of hold-up problems, the exercise of monopoly power by insurers leads clients to undertake socially costly self-protection, leading to suboptimal levels of insurance. Clients can exploit information asymmetries to offset the bargaining power of the insurer, but this process is also socially costly. Hence, competitive markets for insurance will yield a Pareto-superior outcome to the constrained Pareto-optimum reached in markets where insurers have monopoly power. More generally, in a bargaining situation, an increase in the bargaining power of clients will increase social welfare.

The Geneva Risk and Insurance Review (2009) 34, 47-73. doi:10.1057/grir.2008.15

Keywords: insurance; bargaining power; principal-agent; monopolistic insurer

\section{Introduction}

A wide variety of economic relationships have been modelled as contracts between a principal and an agent, made under conditions of imperfect and asymmetric information. Examples include contracts between employers and employees (Yellen, 1984), landlords and sharecroppers (Newbery, 1977; Braverman and Stiglitz, 1986), or regulators and firms (Baron and Myerson, 1982). In most, although not all, cases, such contracts involve the provision of some form of risk-sharing between the agent, who undertakes an action with risky outcomes, and the principal who can make and receive payments that can insure agents against risk. Insurance may therefore be regarded as the 
paradigmatic case of a principal-agent relationship, where the insurer is the principal and the client is the agent.

Principal-agent relationships typically raise the problem of moral hazard, arising from the fact that the principal is imperfectly informed regarding the state of nature, and therefore cannot infer the agent's action from the observed outcome. In addition, such relationships normally involve some element of bargaining, frequently under conditions of unequal bargaining power. Both of these problems have been the subject of large bodies of literature.

Arrow (1963) showed how the concept of "moral hazard", long known to insurers, could be interpreted in terms of decisions under uncertainty. This insight was developed by many subsequent writers, notably Grossman and Hart (1983) who showed how moral hazard could be interpreted in terms of "hidden action", and Arnott and Stiglitz (1988), who pointed to a range of difficulties arising in the "output state" representation of uncertainty used by Grossman and Hart (1983). Quiggin and Chambers (1998) showed how the moral hazard problem could be represented in the state space framework commonly used to analyse choice under uncertainty. This representation allows moral hazard problems to be incorporated into analyses undertaken in a state space framework.

In all of these analyses, the loss to be insured is fixed, and the equilibrium bargain is Pareto-efficient. In many cases of interest, however, the client has the capacity to take action that will affect the occurrence and magnitude of gains and losses. This arises most obviously in the case of agricultural insurance, where the loss to be insured is a loss of production because of climatic shocks or insect infestation, and clients may undertake such actions as the application of fertiliser and pesticides (Miranda, 1991; Horowitz and Lichtenberg, 1993; Chambers and Quiggin, 1996). However, the same issues arise whenever clients have the capacity to undertake self-insurance or self-protection (Ehrlich and Becker, 1972; Lewis and Nickerson, 1989; Quiggin, 2002). When clients are engaged in production, the insurance contract will affect their productive decisions and their productive decisions will affect their reaction to an insurance contract, even in the absence of the kind of private information that produces moral hazard problems.

The existence of moral hazard problems raises the possibility that the distribution of bargaining power may affect the efficiency of the insurance contract, and hence the necessity of integrating principal-agent theory with bargaining theory. Important concerns of bargaining theory are to formulate precise notions of bargaining power and to formalise the intuition that parties with greater bargaining power or lower levels of risk aversion will secure more favourable outcomes. Kihlstrom and Roth (1982) analyse bargaining over insurance in the case where clients facing known risks bargain with a monopolistic insurer. They show that the insurer will prefer to bargain with a 
more risk-averse client. This result was also derived independently by Schlesinger (1984). The same result is obtained, with a more sophisticated model of bargaining, by Viaene et al. (2002). The problem of bargaining under uncertainty, where the agreement or disagreement outcome may be uncertain, has also been analysed extensively (Riddell, 1981; Safra et al., 1990).

Another concern arising in the analysis of bargaining over contracts is that of hold-up problems (Klein et al., 1978) in which one party makes a fixed investment whose value depends on the subsequent decisions of a specific contracting partner. An excellent summary of the hold-up literature is given by Holmstrom and Roberts (1998). In the insurance context, the hold-up problem arises because the client may choose to undertake, or not to undertake, costly self-insurance to improve the ultimate outcome of bargaining. Consider, for example, a building owner who seeks insurance against risks such as fire. Some actions that affect the riskiness of outcomes, such as the installation of smoke alarms, may be undertaken after a contract is signed. However, others, such as the choice of building materials and the design of sprinkler systems must be undertaken in advance. ${ }^{1}$

Our central result is that, in the presence of hold-up problems, the exercise of monopoly power by insurers leads clients to undertake socially costly selfinsurance, leading to suboptimal levels of insurance. Clients can exploit information asymmetries to offset the bargaining power of the insurer, but this process is also socially costly. Hence, competitive markets for insurance will yield a potential Pareto improvement relative to the constrained Paretooptimum reached in markets where insurers have monopoly power. More generally, in a bargaining situation, an increase in the bargaining power of clients will increase social welfare.

The paper is organised as follows. Section 1 presents the model of statecontingent production, and derives the client's optimal output in the absence of insurance. It is shown that, in the absence of insurance, risk-averse clients will engage in self-insurance, trading off (weakly) lower mean net returns for less risk.

Section 2 describes the sequence involved in contracting for insurance. Three cases are examined: the first-best case in which the optimal contract, conditional on both the state of nature and the production decisions of the client is available; the second best (or noncontractible-effort allocation) case in which the client must invest in advance of contracting, producing a hold-up problem; and the third-best in which the hold-up problem is combined with moral hazard problems because of asymmetric information. A converse to the main result of Section 1 is derived, showing that any insurance contract must

\footnotetext{
${ }^{1}$ We are indebted to a referee for suggesting this example.
} 
50

provide the client with a state-contingent payment vector that has (weakly) less risk and lower mean than the state-contingent output vector.

The remaining sections examine how the relative bargaining power of the insurer and client affect production decisions and the insurance contract for each of the three cases. Section 3 deals with the polar case of monopoly, where the contract maximises the insurer's profit, subject to the reservation constraint that the client must be no worse off than under self-insurance. Section 4 deals with the opposite polar case where insurers compete to offer the contract that maximises the welfare of the client, subject to a zero-expected-profit constraint. Section 5 presents the general Nash bargaining solution of which the monopoly and competitive solutions are special cases. Finally, some concluding comments are offered.

\section{Model}

We use upper-case letters to denote state-independent scalars such as the expected output $Z$ and the insurer's expected profit $P$, lower-case letters to denote state-dependent scalars such as output $z_{s}$ in state $s$ and boldface to denote vectors such as the state-contingent output vector $\mathbf{z}$.

We consider the case of two states of nature, labelled so that, in a sense made precise below, state 1 is favourable and state 2 is unfavourable. Production is undertaken by the client, who uses a vector of inputs $\mathbf{x} \in \Re^{N}$ to produce a vector of state-contingent outputs $\mathbf{z} \in \Re^{S}$.

The distinction between inputs, committed ex ante, and outputs realised ex post is standard. However, in practice, some inputs may be committed after the state of nature is realised. To take this into account, the vector $\mathbf{z}$ may be viewed as a netput, with inputs committed ex post being treated as negative elements of $\mathbf{z}$.

We focus on the simple case $S=2$, but much of the analysis is applicable to more general state spaces, including continuous state spaces.

Clients jointly choose the pair $(\mathbf{x}, \mathbf{z})$ from a feasible technology set

$$
T=\{(\mathbf{x}, \mathbf{z}): \mathbf{x} \text { can produce } \mathbf{z}\} .
$$

Thus, the technology may be summarised by the family of feasible output sets

$$
\mathbf{Z}(\mathbf{x})=\{\mathbf{z}:(\mathbf{x}, \mathbf{z}) \in T\} .
$$

The output $z_{s}$ is observed if state of nature $s$ is realised. The general properties of state-contingent production technologies are discussed by Chambers and Quiggin (2000).

Where the state space is continuous, state-contingent output vectors may be interpreted as probability distributions over incomes (Racionero and Quiggin, 
2006). In particular, the model includes as a special case the "output state" representation of production under uncertainty, where input choices determine a probability distribution over a discrete set of outputs, as in Grossman and Hart (1983). The general logic of the state-contingent framework developed here applies to the "output state" representation. However, some results do not extend to the very simplest case of this model, where a scalar effort variable determines the relative probabilities of two output levels (low and high).

The distinction between the state-contingent approach and the output state approach may be illustrated by considering the example of agricultural production, discussed in more detail by Chambers and Quiggin (2000). Although many variables affect agricultural output, we will simplify by supposing that the only relevant variable is rainfall. In the state-contingent approach, there are two states of nature, corresponding to normal rainfall and drought. Farmers determine the output in the two states of nature by their allocation of inputs $\mathbf{x}$. At the margin, an increase in the allocation of effort to a given activity, such as an increase in the area planted, will typically yield a higher marginal return in the normal state than in the drought state. However, there are activities, such as the development of irrigation systems for cropping, or the use of fodder crops for haymaking in conjunction with livestock production, that will produce a larger marginal benefit in the drought state than in the normal state. Hence, farmers can choose, by their allocation of effort, to increase output in the drought state at the expense of production in the normal state, or vice versa.

The output-state representation of self-protection (Ehrlich and Becker, Grossman and Hart) is superficially similar, in that ex post output only takes two values. However, these values (low and high) are fixed exogenously. Effort by the producer reduces the probability of the low output and correspondingly increases the value of the high output. However, as the variance of a two-point distribution is maximised when the probabilities are equal, the effect of increased effort on the riskiness of output is indeterminate. After adjusting for changes in mean output, increased effort increases risk for high initial values of the low output and reduces risk for low initial values. Hence, there is no necessary relationship between risk aversion and self-protection.

The state-contingent model is, however, consistent with the description of self-insurance offered by Ehrlich and Becker, in which the loss associated with an adverse state is mitigated. In the state-contingent framework, self-insurance against risk is represented by the production of a state-contingent output vector that has higher output in the less favourable state of nature $\left(z_{1}\right.$ in Figure 1) and more output in the more favourable state $\left(z_{2}\right.$ in Figure 1) than would be chosen by a risk-neutral producer, maximising the expected value of output. As shown below, in the absence of insurance, risk-averse producers will generally undertake self-insurance. 


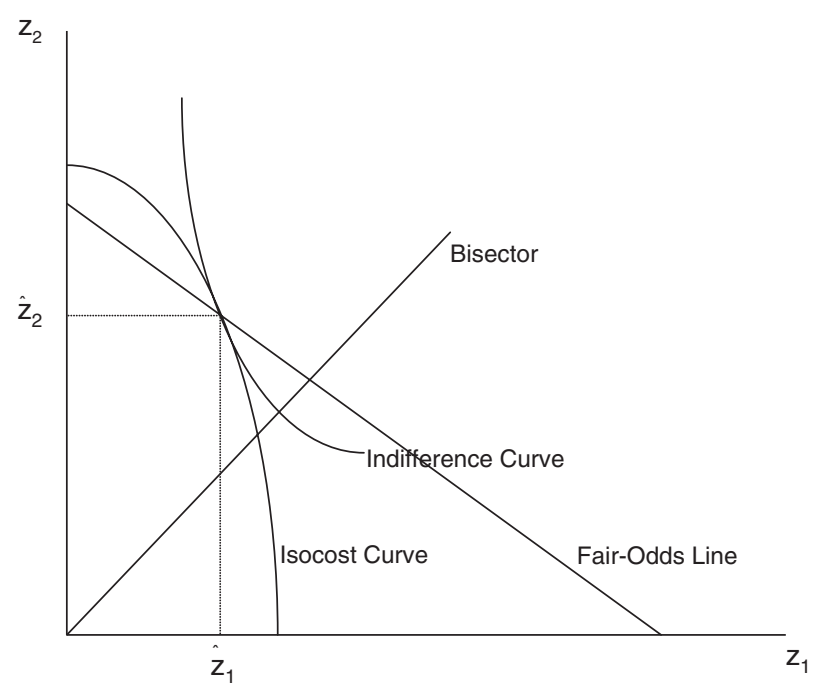

Figure 1. Equilibrium without insurance.

The effort cost function

The client's ex post preferences are of the net returns form

$$
w(y, \mathbf{x})=u(y-g(\mathbf{x})),
$$

where $u$ is a state-independent differentiable, concave, strictly increasing von Neumann-Morgenstern utility function, $y$ is the return to the client, and $g$ is a strictly convex and increasing function. ${ }^{2}$ Letting

$$
C(\mathbf{z})=\min \{g(x): \mathbf{z} \in \mathbf{Z}(x)\},
$$

the client's maximum expected utility, given state-contingent payments $y_{1}$ and $y_{2}$, and consistent with producing the state-contingent output vector $\left(z_{1}, z_{2}\right)$ is

$$
E[w(y, \mathbf{x})]=\pi_{1} u\left(y_{1}-C\left(z_{1}, z_{2}\right)\right)+\pi_{2} u\left(y_{2}-C\left(z_{1}, z_{2}\right)\right),
$$

where $\pi_{s}, s=1,2$, is the client's subjective probability of state $s$, and $E$ is the expectations operator, taken with respect to the probability vector $\left(\pi_{1}, \pi_{2}\right)$.

${ }^{2}$ This objective function, referred to as utility of net returns, differs from that commonly used in the literature on principal-agent relationships, in which preferences over income are independent of effort (Grossman and Hart, 1983; Quiggin and Chambers, 1998). The alternative formulations of the objective function are equivalent if the utility function displays constant absolute risk aversion, as in Holmstrom and Milgrom (1987). 
Assumption 1 The effort-cost function $C: \Re^{2} \rightarrow \Re$ is convex, strictly increasing and twice differentiable in each argument.

Following Chambers and Quiggin (2000), we define a state-contingent output vector $\left(z_{1}, z_{2}\right)$ as inherently risky if

$$
C\left(z_{1}, z_{2}\right) \leqslant C(\overline{\mathbf{z}})
$$

where

$$
\overline{\mathbf{z}}=\pi_{1} z_{1}+\pi_{2} z_{2}, \pi_{1} z_{1}+\pi_{2} z_{2} .
$$

Here the terminology reflects the fact that, at a given level of cost for inherently risky outputs, the client must sacrifice expected output to remove uncertainty from production. Notice, in particular, that if this condition is not satisfied, a risk-averse client can always achieve perfect self-insurance by choosing to produce the riskless output $\overline{\mathbf{z}}$, which yields the same expected output as the risky $\left(z_{1}, z_{2}\right)$, but at lower cost. By the monotonicity of the client's preference function and his risk aversion, the riskless output vector will thus always be strongly preferred to the risky output vector. ${ }^{3}$

We now formalise the claim that state 1 is favourable and state 2 is unfavourable. We define $\left(z_{1}, z_{2}\right)$ as monotonic if $z_{1} \leqslant z_{2}$ and impose.

Assumption 2 Any inherently risky $\left(z_{1}, z_{2}\right)$ is monotonic.

That is, beginning with a riskless output $\overline{\mathbf{z}}$, the only way to reduce costs while holding expected output constant is to set $z_{1}<z_{2}$.

To guarantee the existence of a non-trivial optimum we require

Assumption 3 There exists $\mathbf{z}$ such that:

$$
Z=\pi_{1} z_{1}+\pi_{2} z_{2}>C(\mathbf{z}) .
$$

Defining expected net social output

$$
\Pi(\mathbf{z})=\pi_{1} z_{1}+\pi_{2} z_{2}-C(\mathbf{z}),
$$

Assumption 3 states that there exists $\mathbf{z}$ such that $\Pi(\mathbf{z})>0$.

\footnotetext{
${ }^{3}$ It may appear that all stochastic technologies are inherently risky. This is false as Chambers and Quiggin (2000) demonstrate.
} 
The client's problem without insurance contracts

We first consider the problem where the client is the residual claimant, and does not contract with an insurer. The client receives net return

$$
n_{s}=z_{s}-C(\mathbf{z})
$$

in state $s$, occurring with probability $\pi_{s}$.

Thus, for the case of two states of nature, the client seeks to maximise

$$
W(\mathbf{n})=\pi_{1} u\left(n_{1}\right)+\pi_{2} u\left(n_{2}\right) .
$$

Denoting $\partial C / \partial z_{s}$ by $C_{s}$, the client's first-order conditions are of the form

$$
\begin{array}{r}
\pi_{s} u^{\prime}\left(z_{s}-C\left(z_{1}, z_{2}\right)\right)-\left(\pi_{1} u^{\prime}\left(z_{1}-C\left(z_{1}, z_{2}\right)\right)\right. \\
\left.\quad+\pi_{2} u^{\prime}\left(z_{2}-C\left(z_{1}, z_{2}\right)\right)\right) C_{s}=0 \quad s=1,2
\end{array}
$$

with equality at an interior solution, and are illustrated in Figure 1 by a tangency between the client's indifference curve and isocost curve. Under the stated conditions, a unique interior optimum will exist. We define

$$
\hat{\mathbf{z}}=\arg \max _{\mathbf{z}} W(\mathbf{z}-C(\mathbf{z}) \mathbf{1})
$$

to be the solution to the client's maximisation problem. We denote the associated vector of net returns by $\hat{\mathbf{n}}$ and the expected net return by $\hat{\mathbf{N}}$.

We first observe:

Lemma 1 Under the stated conditions, the optimal choice $\left(\hat{z}_{1}, \hat{z}_{2}\right)$ is inherently risky and monotonic.

Proof That $\left(\hat{z}_{1}, \hat{z}_{2}\right)$ is inherently risky follows from the fact that preferences preserve second-order stochastic dominance. For $\left(\hat{z}_{1}, \hat{z}_{2}\right)$ not inherently risky, the vector $\left(z_{1}-C(\mathbf{z}), z_{2}-C(\mathbf{z})\right)$ is dominated by $(\hat{Z}-C(\overline{\mathbf{z}}), \hat{Z}-C(\overline{\mathbf{z}}))$ where

$$
\hat{Z}=\pi_{1} \hat{z}_{1}+\pi_{2} \hat{z}_{2} .
$$

Monotonicity follows by Assumption 2.

A risk-neutral client chooses $\mathbf{z}$ to maximise expected net return

$$
\begin{aligned}
N(\mathbf{z}) & =Z-C(\mathbf{z}) \\
& =\pi_{1} z_{1}+\pi_{2} z_{2}-C\left(z_{1}, z_{2}\right) .
\end{aligned}
$$

The risk-neutral optimum choice of $\mathbf{z}$ is denoted $\mathbf{z}^{R N}$ and the associated expected profit is denoted $N^{R N}$. Visually it coincides with a tangency between 
the fair-odds line, with slope $-\left(\pi_{1} / \pi_{2}\right)$, and the client's isocost curve. It will also be useful to define, for any cost level $C$,

$$
\mathbf{z}^{R N}(C)=\arg \max _{\mathbf{z}}\left\{\pi_{1} z_{1}+\pi_{2} z_{2}: C\left(z_{1}, z_{2}\right) \leqslant C\right\},
$$

the output vector that maximises expected revenue, conditional on cost level $C$.

Comparing the net returns in the risk-neutral optimum $n^{R N}$ with the preferred choice of a risk-averse client, $\hat{n}$, we must have $N^{R N} \geqslant \hat{N}$, as riskneutral clients choose $z$ to maximise $N(z)$. As the choices of risk-averse clients preserve second-order stochastic dominance, the optimality of $\hat{n}$ must imply

$$
n_{1}^{R N} \leqslant \hat{n}_{1} \leqslant \hat{n}_{2} \leqslant n_{1}^{R N}
$$

Thus, we have

Proposition 2 The optimal net returns for a risk-neutral client $n^{R N}$ must be a mean-increasing spread of the optimal net returns for a risk-averse client $\hat{n}$.

This result is crucial in the analysis that follows, as the class of unconstrained Pareto-optimal allocations are those in which the risk-averse client produces the risk-neutral optimal output $n^{R N}$ and consumes a riskless payment $y$. In the absence of insurance, a risk-averse client will choose an output vector that generates less risky returns, at the cost of lower mean net returns than the maximum available. In the state-contingent setting, the concept of "selfprotection" is naturally interpreted in terms of a trade off between the mean and riskiness of the net returns vector.

The reasoning leading up to Proposition 2 applies to the general class of state-contingent technologies and not merely to the case when $S=2$. In particular, it applies to the general case of the outcome state representation. However, it does not apply to the case of scalar effort and two possible output levels. The problem here is not the output state representation but the fact that for the case $S=2$, this representation implies a stochastic production function technology. In this case, risk-averse clients will commit less effort than riskneutral agents, and will therefore have a lower probability of producing the high output. However, for given effort, they cannot choose a less risky production vector with lower expected returns. As noted by Holmstrom and Milgrom (1987), a stochastic production function with scalar effort allows clients only one degree of freedom, a point developed further by Chambers and Quiggin (2000). Much of the analysis of this paper is therefore not applicable in this case. 


\section{Contracting}

We now consider the principal-agent problem that arises when a risk-neutral insurer contracts with a risk-averse client who is engaged in production under uncertainty. The insurer has the right to specify contract provisions involving a payment $y$ to a client for an observed output $z$, with the insurer receiving $z-y$. Hence, if the contract is accepted, the client receives a state-contingent payment vector $\mathbf{y}(\mathbf{z})$ and the insurer receives the state-contingent income vector $\mathbf{z}-\mathbf{y}$. The client is free to take the contract offered by the insurer or to reject it. If the client rejects the contract, he retains the rights to the state-contingent output vector $\mathbf{z}$. In our framework, therefore, the contracting problem reduces to one of simultaneously picking a state-contingent output vector for the client and a state-contingent payment vector for the insurer. The approach, therefore, is general enough to permit any degree of interlinkage of contract stipulations between the client and the insurer.

We consider two polar cases in relation to the insurer's bargaining power. In the competitive case, we assume that competition among potential insurers drives expected profit to zero. Hence, the problem is one of designing a contract to maximise the client's expected utility subject to the constraint that the insurer must make zero expected profit. In the other polar case, we assume that the insurer has complete monopoly power. Thus, the problem is one of maximising the insurer's expected profit, subject to the constraint associated with the client's right to reject the contract proposed by the insurer and receive instead the output vector $\mathbf{z}$.

This interaction is represented as an extensive-form game. We consider three possible information structures. In all cases the client can observe, ex post, the state of nature $s$, and the insurer can observe, ex post, the output $z$.

First-best case: In the first-best case, the insurer can observe the state of nature ex post, and can commit to offer a payment schedule $\mathbf{y}(\mathbf{z})$ if the client chooses output vector $\mathbf{z}$. The timing is as follows:

1. The insurer commits to a payment schedule $\mathbf{y}^{F B}$ contingent on the client producing $\mathbf{z}^{F B}$.

2. The client accepts or rejects the insurer's contract (rejection is represented as setting $\mathbf{y}=\mathbf{z}$ ).

3. The client chooses the output vector $\mathbf{z}=\left(z_{1}, z_{2}\right)$.

4. Nature chooses $s \in\{1,2\}$.

5. The client and the insurer observe the state of nature $s$, and the output $z_{s}^{F B}$.

6. If the client accepted the contract at stage 2 and produced $\mathbf{z}^{F B}$, she receives $n_{s}^{F B}=y_{s}^{F B}-C\left(\mathbf{z}^{F B}\right)$, and the insurer receives $z_{s}^{F B}-y_{s}^{F B}$. If the contract was rejected, the client receives $n_{s}=z_{s}-C(\mathbf{z})$ and the insurer receives zero. 
Second-best case: In the second-best or noncontractible effort allocation case, the choice of effort level and the allocation of effort to determine a statecontingent output vector for the client are non-contractible ex ante. However, the insurer can make the contracted payment conditional on the state of nature and the observed ex post output. This kind of contract may be observed, for example, in commercially provided crop insurance against specified risks such as hailstorm damage, or in insurance against rainfall for public events. Except where the insurer has no bargaining power, the second-best case gives rise to a hold-up problem for the client, who must choose the state-contingent output vector $\mathbf{z}^{S B}$ before the insurer determines the payment schedule $\mathbf{y}^{S B}$. This is exactly analogous to the classic hold-up problem analysed by Klein et al. (1978). The bargaining sequence is:

1. The client chooses the output vector $\mathbf{z}^{S B}=\left(z_{1}^{S B}, z_{2}^{S B}\right)$.

2. The insurer offers a payment schedule $\mathbf{y}^{S B}=\left(y_{1}^{S B}, y_{2}^{S B}\right)$ for output $\mathbf{z}^{S B}$ (or equivalently, offers a payment $y_{S}^{S B}-z_{S}^{S B}$ conditional on the occurrence of state $s$ ).

3. The client accepts or rejects the insurer's contract.

4. Nature chooses $s \in\{1,2\}$.

5. The client and the insurer observe the state of nature $s$, and the output $z_{s}^{S B}$.

6. If the client accepted the contract at stage 3 , she receives $n_{s}^{S B}=y_{\mathrm{s}}^{S B}-C\left(\mathbf{z}^{S B}\right)$, and the insurer receives $z_{s}^{S B}-y_{S}^{S B}$. If the contract was rejected, the client receives $n_{s}=z_{\mathrm{s}}^{S B}-C(\mathbf{z})$ and the insurer receives zero.

Third-best case: In the third-best or asymmetric-information with hold-up case, the insurer can observe ex post output $z_{s}$, but not the state of nature. This is the situation with publicly provided multiple risk crop insurance in the United States. Hence the contract offered by the insurer must be incentive-compatible. The timing is:

1. The client chooses the output vector $\mathbf{z}^{T B}=\left(z_{1}^{T B}, z_{2}^{T B}\right)$.

2. The client announces an output plan $\tilde{\mathbf{z}}^{T B}=\left(\tilde{z}_{1}^{T B}, \tilde{z}_{2}^{T B}\right.$ ) (in incentivecompatible equilibria, $\mathbf{z}^{T B}=\tilde{\mathbf{z}}^{T B}$ ).

3. The insurer offers a payment schedule $\mathbf{y}^{T B}=\left(y_{1}^{T B}, y_{2}^{T B}\right)$ for output $\tilde{\mathbf{z}}^{T B}=\left(\tilde{z}_{1}^{T B}, \tilde{z}_{2}^{T B}\right)$.

4. The client accepts or rejects the insurer's contract (rejection is represented as setting $\mathbf{y}^{T B}=\mathbf{z}^{T B}$ ).

5. Nature chooses $s \in\{1,2\}$.

6. The client observes the state of nature $s$.

7. The client reports state $\tilde{s}$, (in incentive-compatible equilibria $\tilde{s}=s$ ).

8. The insurer observes the ex post output $z_{s}^{T B}$.

9. If the client accepted the contract at stage 4 and produced $z_{S}^{T B}=\tilde{z}_{\tilde{s}}^{T B}$, the client receives $n_{s}^{T B}=y_{s}^{T B}-C\left(\mathbf{z}^{T B}\right)$, but if $z_{s}^{T B} \neq \tilde{z}_{\tilde{S}}^{T B}$ the client receives an 
arbitrarily large negative payoff. If the contract was rejected, the client receives $n_{s}=z_{s}^{T B}-C(\mathbf{z})$, and the insurer receives zero.

The focus of our analysis is on the interaction between the game structure and the relative bargaining power of the insurer and client. We first observe the following result, which is valid for any of the information structures considered in this paper.

Proposition 3 Suppose $z_{1} \leqslant z_{2}$. Then any contract which is acceptable to the client and which yields non-negative expected profits to the insurer must satisfy $z_{1} \leqslant y_{1}, y_{2} \leqslant z_{2}$.

Proof Suppose to the contrary that $y_{2}>z_{2}$. Then the contract can only be profitable if $y_{1}<z_{1}$ and

$$
\pi_{1} y_{1}+\pi_{2} y_{2}<\pi_{1} z_{1}+\pi_{2} z_{2}
$$

This means that $\left(z_{1}, z_{2}\right)$ second-order stochastically dominates $\left(y_{1}, y_{2}\right)$ so that acceptance of the contract would make the client worse off. Other violations of the conditions can be dealt with similarly.

\section{Monopolistic insurers}

In the monopolistic case, a single insurer contracts with clients by specifying an output vector $\left(z_{1}, z_{2}\right)$ and payment vector $\left(y_{1}, y_{2}\right)$. Clients must choose whether to produce the output vector $\left(z_{1}, z_{2}\right)$ and receive the payment vector $\left(y_{1}, y_{2}\right)$ proposed by the insurer, or to produce some other output vector (in which case they must self-insure). Then, after committing to $\left(z_{1}, z_{2}\right)$, clients have the opportunity to accept or decline the contract offered by the insurer.

\section{First-best case}

In the first-best case, the insurer can commit in advance to providing the client with a given utility level, conditional on accepting the proposed contract. If the insurer's proposed contract yields the client less than $C E(\hat{\mathbf{n}})$, the certainty equivalent of the net returns vector available in the absence of insurance, the client's best response is to reject the offer and produce $\hat{\mathbf{z}}$. If the contract yields at least $C E(\hat{\mathbf{n}})$, the client's best response is to produce the output proposed by the insurer and to accept the contract. 
Hence, the insurer's problem is:

$$
\max _{\mathbf{y}}\left\{\pi_{1}\left(z_{1}-y_{1}\right)+\pi_{2}\left(z_{2}-y_{2}\right)\right\}
$$

subject to the constraint

$$
\pi_{1} u\left(y_{1}-C\left(z_{1}, z_{2}\right)\right)+\pi_{2} u\left(y_{2}-C\left(z_{1}, z_{2}\right)\right) \geqslant u(C E(\hat{\mathbf{n}})) .
$$

The insurer will, therefore, choose $\left(z_{1}^{F B}, z_{2}^{F B}\right)$ to maximise

$$
P=\pi_{1} z_{1}+\pi_{1} z_{2}-C\left(z_{1}, z_{2}\right)
$$

and make a state-independent payment $Y^{F B}$ such that

$$
Y^{F B}-C\left(\mathbf{z}^{F B}\right)=C E(\hat{\mathbf{n}}) .
$$

It is obvious that $Z^{F B}=Z^{R N}$, so that the insurer's expected profit is

$$
\begin{aligned}
P^{F B} & =Z^{R N}-Y^{F B} \\
& =\Delta_{1}(\hat{\mathbf{z}})+\Delta_{2}(\hat{\mathbf{z}}),
\end{aligned}
$$

where

$$
\Delta_{1}(\hat{\mathbf{z}})=\left[Z^{F B}-C\left(z_{1}^{F B}, z_{2}^{F B}\right)\right]-\left[\hat{Z}-C\left(\hat{z}_{1}, \hat{z}_{2}\right)\right],
$$

which is the cost of self-insurance by the client, and

$$
\Delta_{2}(\hat{\mathbf{z}})=\hat{P}-C E(\hat{\mathbf{n}})
$$

is the client's risk premium.

The solution is illustrated in Figure 2 by having the client produce at the point of tangency between the fair-odds line and the isocost curve for $C\left(\mathbf{z}^{R N}\right)$ and then having the insurer define an implicit indemnity structure that leaves the client at the point of intersection', $\mathrm{CE}(\hat{n})$ between the bisector and the client's indifference curve through $\hat{\mathbf{n}}$.

Comparative statics for this solution are straightforward. Changes in the client's risk aversion have no effect on the optimal output. However, the less risk-averse the client, the smaller the insurer's profit.

We have

Proposition 4 In the first-best solution, the insurers profit is lower, the less risk-averse is the client, and is equal to zero when the client is risk-neutral.

\section{Second-best (noncontractible effort allocation) case}

We next consider the case when the insurer can observe the state of nature, but cannot commit in advance to a conditional payment $\mathbf{y}(\mathbf{z})$. Hence, the client commits to the production vector $\left(z_{1}, z_{2}\right)$ before negotiating with the insurer. 


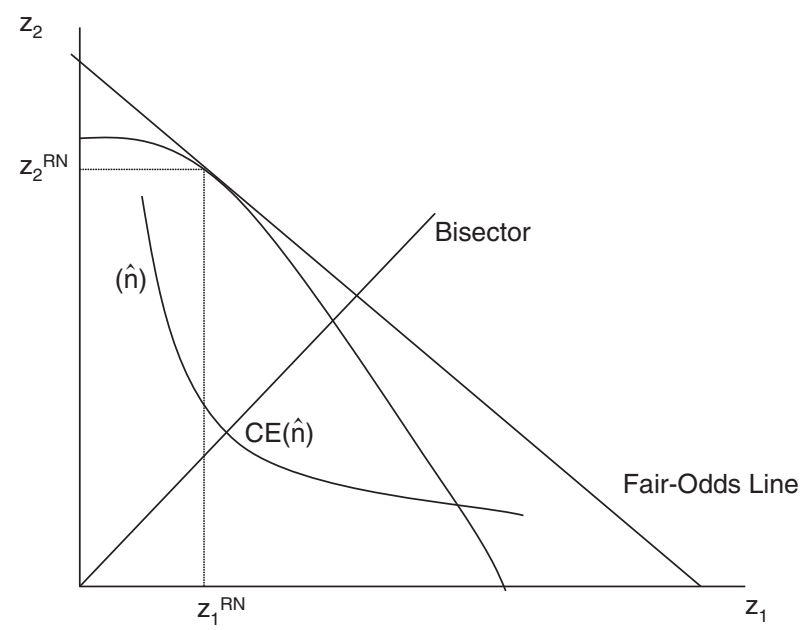

Figure 2. First-best equilibrium.

The insurer must then offer a payment vector $\left(y_{1}, y_{2}\right)$, which the client can either accept or decline. As the insurer can observe the state of nature and the client's output, the client must announce $\tilde{s}=s$ and must therefore announce $\tilde{\mathbf{z}}=\mathbf{z}$. Given that the client has committed to, and announced, the output $\mathbf{z}$, the best response for the insurer is to offer the client exactly $W(\mathbf{z}-C(\mathbf{z}) \mathbf{1})$, the utility the client would get from consuming the output $\left(z_{1}, z_{2}\right)$ chosen in stage 1 . Hence by backward induction, the optimal strategy for the client is to choose the output $\hat{\mathbf{z}}$ that maximises this utility, that is, the same output that would be chosen in the absence of insurance. Hence, this game has a unique (weak) perfect Bayesian equilibrium, which we now explore in detail.

The insurer's objective function is:

$$
\max _{\mathbf{y}} \pi_{1}\left(y_{1}-z_{1}\right)+\pi_{2}\left(y_{2}-z_{2}\right)
$$

subject to the constraint

$$
\pi_{1} u\left(y_{1}-C\left(z_{1}, z_{2}\right)\right)+\pi_{2} u\left(y_{2}-C\left(z_{1}, z_{2}\right)\right) \geqslant u(C E(\hat{\mathbf{n}}))
$$

which requires that the client, having committed to the vector $\left(z_{1}, z_{2}\right)$, vector will find the insurer's contract at least as attractive as the alternative of consuming $\left(z_{1}, z_{2}\right)$.

In the optimal solution, the insurer will offer a state-independent payment of $\hat{Y}$, where

$$
\hat{Y}-C(\hat{\mathbf{z}})=C E(\hat{\mathbf{n}}) .
$$


The insurer's expected profit is

$$
\begin{aligned}
\hat{P} & =\hat{Z}-\hat{Y} \\
& =P^{F B}-\Delta_{1}(\hat{\mathbf{z}}) \\
& =\Delta_{2}(\hat{\mathbf{z}}) .
\end{aligned}
$$

Under monopoly, the second-best case involves a welfare loss of $\Delta_{1}(\hat{\mathbf{z}})$ relative to the first-best. This loss reflects the cost of self-insurance, in excess of the optimal amount, undertaken by the client in anticipation of the hold-up problem associated with the insurer's use of monopoly power.

\section{Third-best (asymmetric information with hold-up) case}

The asymmetric information monopolistic case with hold-up will be referred to as the third-best, as both the insurer's monopoly power and the client's private information reduce aggregate welfare relative to the first-best. Thus, the outcome is affected both by the hold-up problem and by moral hazard.

The insurer's best response, given an announced output $\tilde{\mathbf{z}}$, is to offer a payment schedule $\mathbf{y}$ yielding the client $W(\tilde{\mathbf{z}}-C(\tilde{\mathbf{z}}) \mathbf{1})$ if $\tilde{\mathbf{z}}$ is produced, and $W \leqslant W(\tilde{\mathbf{z}}-C(\tilde{\mathbf{z}}) \mathbf{1})$ if any $\mathbf{z} \neq \tilde{\mathbf{z}}$ is produced. Hence, in any perfect Bayesian equilibrium, the client produces and announces $\hat{\mathbf{z}}$, yielding certainty-equivalent outcome $C E(\hat{\mathbf{n}})$.

The outcome in state $s$ is that the insurer's payoff is $z_{s}-y_{s}$, and the client's payoff is $y_{s}-C\left(z_{1}, z_{2}\right)$. Hence the insurer's problem becomes

$$
\max _{\mathbf{y}} \pi_{1}\left(y_{1}-\hat{z}_{1}\right)+\pi_{2}\left(y_{2}-\hat{z}_{2}\right)
$$

subject to the constraints:

$$
\begin{array}{ll}
\text { (T.1) } & \pi_{1} u\left(y_{1}-C\left(\hat{z}_{1}, \hat{z}_{2}\right)\right)+\pi_{2} u\left(y_{2}-C\left(\hat{z}_{1}, \hat{z}_{2}\right)\right) \geqslant u(C E(\hat{\mathbf{n}})) ; \\
\text { (T.2) } & \pi_{1} u\left(y_{1}-C\left(\hat{z}_{1}, \hat{z}_{2}\right)\right)+\pi_{2} u\left(y_{2}-C\left(\hat{z}_{1}, \hat{z}_{2}\right)\right) \\
& \geqslant u\left(y_{1}-C\left(\hat{z}_{1}, \hat{z}_{1}\right)\right) ; \\
\text { (T.3) } & \pi_{1} u\left(y_{1}-C\left(\hat{z}_{1}, \hat{z}_{2}\right)\right)+\pi_{2} u\left(y_{2}-C\left(\hat{z}_{1}, \hat{z}_{2}\right)\right) \\
& \geqslant u\left(y_{2}-C\left(\hat{z}_{2}, \hat{z}_{2}\right)\right) ; \quad \text { and } \\
\text { (T.4) } & \pi_{1} u\left(y_{1}-C\left(\hat{z}_{1}, \hat{z}_{2}\right)\right)+\pi_{2} u\left(y_{2}-C\left(\hat{z}_{1}, \hat{z}_{2}\right)\right) \\
& \geqslant \pi_{1} u\left(y_{2}-C\left(\hat{z}_{2}, \hat{z}_{1}\right)\right)+\pi_{2} u\left(y_{1}-C\left(\hat{z}_{2}, \hat{z}_{1}\right)\right) .
\end{array}
$$

Assuming $z_{1} \leqslant z_{2}$, the incentive compatibility constraints clearly require $y_{1} \leqslant y_{2}$ with strict inequality whenever $z_{1}<z_{2}$. Hence we obtain the following Corollary to Proposition 3. 
62

Corollary 5 Any solution to the asymmetric information problem with nonnegative expected profit for the insurer must have

$$
z_{1} \leqslant y_{1} \leqslant y_{2} \leqslant z_{2}
$$

As $y_{2}<z_{2}$, the option of producing $\left(z_{2}, z_{2}\right)$ and receiving $\left(y_{2}, y_{2}\right)$ under the insurance contract is dominated by the alternative of producing $\mathbf{z}=\left(z_{2}, z_{2}\right)$ and setting $\mathbf{y}=\mathbf{z}$. Also, because $\left(z_{2}, z_{1}\right)$ is not inherently risky, the option of producing $\left(z_{2}, z_{1}\right)$ and receiving $\left(y_{2}, y_{1}\right)$ is dominated by the alternative of setting $\mathbf{z}=\left(y_{2}, y_{1}\right)$ and setting $\mathbf{y}=\mathbf{z}$. In each case, the dominating alternative is dominated by the trivial contract in which the client produces $\hat{\mathbf{z}}$ and receives payment $\mathbf{y}=\hat{\mathbf{z}}$, yielding net returns $\hat{\mathbf{n}}$. Noting that this contract satisfies all the constraints, we observe that the set of feasible contracts yielding $W \geqslant W(\hat{\mathbf{z}}-C(\hat{\mathbf{z}}) \mathbf{1})$ is non-empty. Assuming that $C$ is "sufficiently" convex, the set of feasible contracts will also be compact. Hence, we have:

Lemma There exists an optimal pair $(\mathbf{y}, \mathbf{z})$ satisfying the constraints (T.1) to (T.4). For this pair (y, z), the constraints (T.3) and (T.4) are not binding.

We have proved the following result, previously derived by Grossman and Hart (1983) for the case of where preferences over income are independent of effort.

Proposition 6 In the asymmetric information problem with monopolistic insurance and a net returns objective function, the equilibrium will yield the client's reservation utility.

We can derive an explicit solution to the insurance problem. Let $u_{i}$ denote $u\left(y_{i}-C\left(\hat{z}_{1}, \hat{z}_{2}\right)\right), i=1,2$. Then the solution to the problem takes the form

$$
\begin{aligned}
\pi_{1} u_{1}+\pi_{2} u_{2} & =u(C E(\hat{\mathbf{n}})) \\
& =u\left(y_{1}-C\left(\hat{z}_{1}, \hat{z}_{1}\right)\right) .
\end{aligned}
$$

Hence,

$$
y_{1}-C\left(\hat{z}_{1}, \hat{z}_{1}\right)=C E(\hat{\mathbf{n}})
$$

or

$$
\begin{aligned}
y_{1}(\hat{\mathbf{z}}) & =C E(\hat{\mathbf{n}})+C\left(\hat{z}_{1}, \hat{z}_{1}\right) \\
& =\hat{Y}+C\left(\hat{z}_{1}, \hat{z}_{1}\right)-C\left(\hat{z}_{1}, \hat{z}_{2}\right)
\end{aligned}
$$


and

$$
\begin{aligned}
y_{2}(\hat{\mathbf{z}}) & -C\left(\hat{z}_{1}, \hat{z}_{2}\right) \\
= & u^{-1}\left(\frac{u(C E(\hat{\mathbf{n}}))-\pi_{1} u\left(y_{1}(\hat{\mathbf{z}})-C\left(\hat{z}_{1}, \hat{z}_{2}\right)\right)}{\pi_{2}}\right) \\
= & u^{-1}\left(\frac{u(C E(\hat{\mathbf{n}}))-\pi_{1} u\left(C E(\hat{\mathbf{n}})+C\left(\hat{z}_{1}, \hat{z}_{1}\right)-C\left(\hat{z}_{1}, \hat{z}_{2}\right)\right)}{\pi_{2}}\right) .
\end{aligned}
$$

Thus, the insurer's expected profit is

$$
\begin{aligned}
P^{T B} & =\hat{z}-\pi_{1} y_{1}\left(\hat{z}_{1}, \hat{z}_{2}\right)-\pi_{2} y_{2}\left(\hat{z}_{1}, \hat{z}_{2}\right) \\
& =P^{F B}-\Delta_{1}(\hat{\mathbf{z}})-\Delta_{2}^{T B}(\hat{\mathbf{z}}),
\end{aligned}
$$

where $\Delta_{1}$ is the client's cost of self-insurance as before, and

$$
\Delta_{2}^{T B}(\hat{\mathbf{z}})=\left(\pi_{1} y_{1}(\hat{\mathbf{z}})+\pi_{2} y_{2}(\hat{\mathbf{z}})-C(\hat{\mathbf{z}})\right)-C E(\hat{\mathbf{n}})
$$

is the client's risk premium associated with the requirement for incentivecompatibility. Moreover, we note that $0 \leqslant \Delta_{2}^{T B}(\hat{\mathbf{z}}) \leqslant \Delta_{2}(\hat{\mathbf{z}})$ and

$$
P^{T B}=\Delta_{2}(\hat{\mathbf{z}})-\Delta_{2}^{T B}(\hat{\mathbf{z}}) .
$$

The existence of asymmetric information prevents the insurer from fully insuring the client and capturing the entire risk premium.

The incentive-compatibility constraint implies:

$$
C E^{T B}=\hat{y}_{1}-C\left(\hat{z}_{1}, \hat{z}_{1}\right)
$$

So

$$
\begin{aligned}
\Delta_{2}^{T B} & =\pi_{1} \hat{y}_{1}+\pi_{2} \hat{y}_{2}-C\left(\hat{z}_{1}, \hat{z}_{2}\right)-C E^{T B} \\
& =\pi_{2}\left(\hat{y}_{2}-\hat{y}_{1}\right)-\left(C\left(\hat{z}_{1}, \hat{z}_{2}\right)-C\left(\hat{z}_{1}, \hat{z}_{1}\right)\right) .
\end{aligned}
$$

\section{Competitive insurance}

We now consider the competitive case, where the insurer's expected profit is zero. In the second-best case, the absence of a hold-up problem arising from the need to deal with a monopolistic insurer means that the client does not need to commit to costly self-insurance before contracting. Hence, the first-best outcome is achieved. Under asymmetric information, the problem of inadequate insurance is mitigated by the capacity of the client to bear more risk than would be the case in the presence of the hold-up problem, although less than in the presence of full insurance. 


\section{First-best and second-best cases}

In the competitive case, the insurer must offer the contract that maximises the client's utility, subject to the insurer making zero expected profit. In the first-best case, the insurer will therefore choose $\left(z_{1}^{F B}, z_{2}^{F B}\right)$ to maximise

$$
N^{F B}=\pi_{1} z_{1}+\pi_{2} z_{2}-C\left(z_{1}, z_{2}\right)
$$

and make the payment $N^{F B}$ in both states of nature. It is obvious that $N^{F B}=N^{R N}$ so that the contract yields the client a welfare gain of

$$
N^{R N}-C E(\hat{\mathbf{n}})=\Delta_{1}(\hat{\mathbf{z}})+\Delta_{2}(\hat{\mathbf{z}})
$$

relative to the equilibrium without insurance.

Competition among insurers ensures that the insurer must offer the most appealing possible contract to the client, subject to the zero-expected-profit constraint. Hence, even in the absence of an ex ante commitment by the insurer, the first-best contract is achievable provided that the state of nature is observable. That is, the second-best equilibrium is the same as the first-best. This common outcome is the same as in the first-best monopoly case, except that all the benefits of the contract go to the client rather than the insurer.

Relative to the monopolistic case, the client is better off and the insurer is worse off in the competitive second-best case, as would be expected. However, unlike the monopolistic case, the outcome in the second-best case is Paretoefficient.

\section{Third-best case}

The asymmetric information case arises when the insurer cannot observe, or at least contract on, either the state of nature $s$ or the output vector $\mathbf{z}$. Hence it is possible for the client to misrepresent the output vector to which she has committed, and support this misrepresentation by misreporting the state of nature where necessary. For example, the client might commit to $\left(z_{1}, z_{1}\right)$ but report that she has committed to $\left(z_{1}, z_{2}\right)$. Whatever state of nature actually occurred, the client would produce $z_{1}$ and report the occurrence of state $1 .{ }^{4} \mathrm{We}$ may confine attention to incentive-compatible equilibria, in which such misrepresentation does not occur.

\footnotetext{
${ }^{4}$ This is the only relevant possibility, assuming $z_{1} \leqslant z_{2}$. As the insurance contract must have $y_{2} \leqslant z_{2}$ by Proposition 1, the option of producing $\left(z_{2}, z_{2}\right)$ and receiving $\left(y_{2}, y_{2}\right)$ under the insurance contract is dominated by the alternative of not contracting and receiving $\left(z_{2}, z_{2}\right)$. Under the assumption of constant returns to scale, the option of producing $\left(z_{2}, z_{1}\right)$ is dominated by a convex combination of the returns available by producing $\left(z_{2}, z_{2}\right)$, yielding $z_{2}-C\left(z_{2}, z_{2}\right)$ and $\left(z_{1}, z_{1}\right)$, yielding $z_{1}-C\left(z_{1}, z_{1}\right)$.
} 
For given $\mathbf{z}$, the optimal payment vector must satisfy

$$
\begin{array}{ll}
\text { (T.1) } & \pi_{1} y_{1}+\pi_{2} y_{2}=\pi_{1} z_{1}+\pi_{2} z_{2} ; \\
\text { (T.2) } & \pi_{1} u\left(y_{1}-C\left(z_{1}, z_{2}\right)\right)+\pi_{2} u\left(y_{2}-C\left(z_{1}, z_{2}\right)\right) \\
& \geqslant u\left(y_{1}-C\left(z_{1}, z_{1}\right)\right) ; \\
\text { (T.3) } & \pi_{1} u\left(y_{1}-C\left(z_{1}, z_{2}\right)\right)+\pi_{2} u\left(y_{2}-C\left(z_{1}, z_{2}\right)\right) \\
& \geqslant u\left(y_{2}-C\left(z_{2}, z_{2}\right)\right) ; \text { and } \\
\text { (T.4) } & \pi_{1} u\left(y_{1}-C\left(z_{1}, z_{2}\right)\right)+\pi_{2} u\left(y_{2}-C\left(z_{1}, z_{2}\right)\right) \\
& \geqslant \pi_{1} u\left(y_{2}-C\left(z_{2}, z_{1}\right)\right)+\pi_{2} u\left(y_{1}-C\left(z_{2}, z_{1}\right)\right) .
\end{array}
$$

As in the monopoly case, only the first and second constraints will bind in equilibrium.

Thus, for any announced $\left(z_{1}, z_{2}\right)$, competition will induce the insurer to offer an output-dependent payment $\mathbf{y}$ that maximises the client's utility subject to the zero-profit constraint

$$
\text { (T.1) } \pi_{1} y_{1}+\pi_{2} y_{2}=\pi_{1} z_{1}+\pi_{2} z_{2}
$$

and the incentive-compatibility constraint

$$
\text { (T.2) } \begin{aligned}
& \pi_{1} u\left(y_{1}-C\left(z_{1}, z_{2}\right)\right)+\pi_{2} u\left(y_{2}-C\left(z_{1}, z_{2}\right)\right) \\
& \geqslant u\left(y_{1}-C\left(z_{1}, z_{1}\right)\right) .
\end{aligned}
$$

Let the optimal solution to this problem be denoted $\mathbf{y}(\mathbf{z})$. We now consider some characteristics of the equilibrium pair $(\mathbf{y}, \mathbf{z})$.

Consider first $\mathbf{y}(\hat{\mathbf{z}})$. As $z_{1} \leqslant y_{1} \leqslant y_{2} \leqslant z_{2}$ and

$$
\begin{gathered}
\pi_{s} u^{\prime}\left(z_{s}-C\left(z_{1}, z_{2}\right)\right)-\left(\pi_{1} u^{\prime}\left(z_{1}-C\left(z_{1}, z_{2}\right)\right)\right. \\
\left.\quad+\pi_{2} u^{\prime}\left(z_{2}-C\left(z_{1}, z_{2}\right)\right)\right) C_{s}=0, \quad s=1,2
\end{gathered}
$$

we must have

$$
\begin{array}{r}
\pi_{1} u^{\prime}\left(y_{1}-C\left(z_{1}, z_{2}\right)\right)-\left(\pi_{1} u^{\prime}\left(y_{1}-C\left(z_{1}, z_{2}\right)\right)\right. \\
\left.+\pi_{2} u^{\prime}\left(y_{2}-C\left(z_{1}, z_{2}\right)\right)\right) C_{1} \leqslant 0, \quad s=1,2 \\
\pi_{2} u^{\prime}\left(y_{2}-C\left(z_{1}, z_{2}\right)\right)-\left(\pi_{1} u^{\prime}\left(y_{1}-C\left(z_{1}, z_{2}\right)\right)\right. \\
\left.+\pi_{2} u^{\prime}\left(y_{2}-C\left(z_{1}, z_{2}\right)\right)\right) C_{2} \geqslant 0, \quad s=1,2 .
\end{array}
$$

Hence, the client would benefit from a change which increased $n_{2}=z_{2}-C\left(z_{1}, z_{2}\right)$ and $y_{2}-C\left(z_{1}, z_{2}\right)$, and reduced $n_{1}=z_{1}-C\left(z_{1}, z_{2}\right)$ and $y_{1}-C\left(z_{1}, z_{2}\right)$ in such a manner as to hold $z_{2}-y_{2}$ and $z_{1}-y_{1}$ constants. Such a change would leave the expected profit equal to zero. Moreover, totally differentiating the right-hand side of the incentive-compatibility constraint yields the following expression for 
66

the change in the client's utility conditional on producing $\left(z_{1}, z_{1}\right)$ :

$$
u^{\prime}\left(y_{1}-C\left(z_{1}, z_{1}\right)\left[d y_{1}-\left(C_{1}\left(z_{1}, z_{1}\right)+C_{2}\left(z_{1}, z_{1}\right)\right) d z_{1}\right]\right.
$$

Observing that $C_{1}\left(z_{1}, z_{1}\right)+C_{2}\left(z_{1}, z_{1}\right) \leqslant 1$, and $d y_{1}=d z_{1} \leqslant 0$, the right-hand side declines, while the left-hand side increases. Hence, the incentive-compatibility constraint is satisfied after the change. It follows that the client will prefer to choose an output vector $\mathbf{z}$ such that

$$
\begin{aligned}
\pi_{1} n_{1}+\pi_{2} n_{2} & \geqslant \pi_{1} \hat{n}_{1}+\pi_{2 \hat{n} 2} \\
n_{1} & \leqslant \hat{n}_{1} \leqslant \hat{n}_{2} \leqslant n_{2} .
\end{aligned}
$$

That is:

Proposition 7 The optimal net returns vector $\mathbf{n}$ in the competitive asymmetric information solution is derived from a mean-increasing spread of $\hat{\mathbf{n}}$

Having derived this result, it is possible to characterise the welfare losses in the competitive asymmetric information solution relative to the first-best. The client's problem at stage 1 is to choose $\mathbf{z}^{C A S}$ to maximise

$$
\pi_{1} u\left(y_{1}(\mathbf{z})-C\left(z_{1}, z_{2}\right)\right)+\pi_{2} u\left(y_{2}(\mathbf{z})-C\left(z_{1}, z_{2}\right)\right),
$$

yielding net returns $\mathbf{n}^{C A S}$. Denote the expected output and net returns by $Z^{C A S}$, $N^{C A S}$.

Relative to the first-best, the client incurs a cost of self-insurance

$$
\Delta_{1}\left(\mathbf{z}^{C A S}\right)+\Delta_{2}\left(\mathbf{z}^{C A S}\right)=N^{R N}-N^{C A S},
$$

and a cost of incomplete insurance

$$
\Delta_{2}\left(\mathbf{z}^{C A S}\right)=N^{C A S}-C E\left(\mathbf{n}^{C A S}\right) .
$$

As noted above, $\mathbf{z}^{C A S}$ is riskier than $\hat{\mathbf{z}}$, and $E\left[\mathbf{n}^{C A S}\right] \geqslant E[\hat{\mathbf{n}}]$. Hence, $\Delta_{1}\left(\mathbf{z}^{C A S}\right) \leqslant \Delta_{1}(\hat{\mathbf{z}})$. Moreover, $C E\left(\mathbf{n}^{C A S}\right) \geqslant C E(\hat{\mathbf{n}})$. Hence,

$$
\Delta_{1}\left(\mathbf{z}^{C A S}\right)+\Delta_{2}\left(\mathbf{z}^{C A S}\right) \leqslant \Delta_{1}(\hat{\mathbf{z}})+\Delta_{2}(\hat{\mathbf{z}}) .
$$

As in the monopoly case, the incentive-compatibility constraint implies that:

$$
C E\left(\mathbf{n}^{C A S}\right)=y_{1}^{C A S}-C\left(z_{1}^{C A S}, z_{1}^{C A S}\right),
$$

so

$$
\begin{aligned}
\Delta_{2}\left(\mathbf{z}^{C A S}\right) & =\pi_{1} y_{1}^{C A S}+\pi_{2} y_{2}^{C A S}-C\left(z_{1}^{C A S}, z_{2}^{C A S}\right)-C E^{C A S} \\
& =\pi_{2}\left(y_{2}^{C A S}-y_{1}^{C A S}\right)-\left(C\left(z_{1}^{C A S}, z_{2}^{C A S}\right)-C\left(z_{1}^{C A S}, z_{1}^{C A S}\right)\right)
\end{aligned}
$$


As the client was free to choose the output level $\hat{\mathbf{z}}$,

$$
\Delta_{1}^{T B}+\Delta_{2}^{T B} \geqslant \Delta_{1}^{C A S}+\Delta_{2}^{C A S}
$$

\section{Bargaining solutions}

In the monopolistic solutions considered above, the insurer's monopoly power allows him to capture the entire rent. Compared with the competitive case, however, the insurer's profit is less than the reduction in the certaintyequivalent income of the client, and there is, therefore, a net social loss. In both the second-best and third-best cases, the client must precommit to an inefficient production vector to secure his reservation utility, creating a hold-up problem. In the third-best case, there is an additional loss relative to the first-best and second-best arising from the insurer's need to offer an incentive-compatible contract to overcome moral hazard problems.

We now consider the possibility of co-operative solutions, in which the client and insurer can contract, ex ante, so as to avoid one or both of these sources of divergence from the first-best. The solution concept applied is that of a Nash bargaining solution. The disagreement point for the second-best and third-best cases is that derived above for the monopoly case. The agreement point may be either the first-best or an asymmetric information solution in which the insurer commits to a payment schedule based on observed output, but the state of nature is not contractible. The relative bargaining power of the parties, measured by the parameter $\alpha$ will be determined by a range of factors, including the competitiveness or otherwise of markets and the institutional framework within which bargaining takes place.

Co-operative bargaining solutions may arise either because clients gain an increase in bargaining power relative to monopolistic insurers or because the externality associated with the client's private information is partially internalised. As an example of the former process, individual bargaining with a monopoly insurer may be replaced by collective bargaining. In an employment relationship, for example, workers may be represented by unions. Alternatively, policies such as employee stock ownership plans may produce some commonality of interest between clients and insurers and thereby lead to the internalisation of externalities.

A crucial observation is that clients anticipating the need to deal with an insurer with substantial bargaining will undertake costly self-insurance to improve the outside option that will form the basis of subsequent bargaining. Hence, the distribution of bargaining power affects the social surplus. 


\section{First-best case}

We first consider the case where the insurer and client can reach the first-best outcome through bargaining. The disagreement point is one in which the client chooses some $\tilde{\mathbf{z}}$, yielding the reservation certainty-equivalent income $C E(\tilde{\mathbf{n}})$. No contracting takes place and the insurer therefore receives zero. ${ }^{5}$ The agreement point is one in which the client produces the first-best output $\mathbf{z}^{F B}=\mathbf{z}^{R N}$ and receives a non-stochastic payment $Y$, yielding net income $Y-C\left(\mathbf{z}^{F B}\right)$. Bargaining therefore determines the payment $Y$ received by the client and the insurer's profit $Z-Y$.

Analysis of bargaining problems requires a cardinal specification of the utility of income under certainty. Diminishing marginal utility of certain income is not necessarily equivalent to risk-aversion under uncertainty even though both may be represented by concavity of the utility function. For simplicity, we assume that utility for both parties is linear in certaintyequivalent income. For the risk-neutral insurer, certainty-equivalent income is equal to expected income. This specification is consistent with the assumption that preferences satisfy the axioms of expected utility; assuming expectedutility preferences, the cardinal utility function $V$ is a monotonic transformation of the expected utility $E[u]$.

The relative bargaining power of the two parties is represented by a parameter $\alpha^{6}{ }^{6}$ Thus, the bargaining problem is to choose $Y$ to maximise

$$
\hat{V}=\left(\left(Y-C\left(\mathbf{z}^{F B}\right)\right)-C E(\tilde{\mathbf{n}})\right)^{\alpha} P^{1-\alpha},
$$

where $P=Z-Y$.

The first-order condition on $Y$ is:

$$
\begin{aligned}
& \alpha\left(\left(Y-C\left(\mathbf{z}^{F B}\right)\right)-C E(\tilde{\mathbf{n}})\right)^{\alpha-1} P^{1-\alpha} \\
& \quad=(1-\alpha)\left(\left(Y-C\left(\mathbf{z}^{F B}\right)\right)-C E(\tilde{\mathbf{n}})\right)^{\alpha} P^{-\alpha}
\end{aligned}
$$

or

$$
\frac{\left(\left(Y-C\left(\mathbf{z}^{F B}\right)\right)-C E(\tilde{\mathbf{n}})\right)}{P}=\frac{\alpha}{(1-\alpha)} .
$$

\footnotetext{
${ }^{5}$ Note that the insurer may contract with other clients, so that his income in the event of disagreement is not equal to zero. The existence of outside income will be reflected in relative bargaining power.

${ }^{6}$ If utility functions display diminishing marginal utility of income, commonly referred to in the bargaining literature as risk-aversion, the curvature of the cardinal utility functions may be incorporated in the determination of $\alpha$.
} 
As in the analysis of Kihlstrom and Roth (1982), the greater the bargaining power of the client, the higher is the payment $Y$.

Totally differentiating with respect to $C E(\tilde{\mathbf{n}})$ and rearranging yields

$$
(1-\alpha)=(1-\alpha) \frac{\partial Y}{\partial C E(\tilde{\mathbf{n}})}-\alpha \frac{\partial P}{\partial C E(\tilde{\mathbf{n}})},
$$

or as

$$
\begin{gathered}
\frac{\partial Y}{\partial C E(\tilde{\mathbf{n}})}+\frac{\partial P}{\partial C E(\tilde{\mathbf{n}})}=0 \\
\frac{\partial Y}{\partial C E(\tilde{\mathbf{n}})}=(1-\alpha) .
\end{gathered}
$$

Hence, the client's final share of income is increasing in $C E(\tilde{\mathbf{n}})$, and the optimal choice for the client is $\tilde{\mathbf{z}}=\hat{\mathbf{z}}$. However, because the actual output is $\mathbf{z}^{F B}$, the choice of $\tilde{\mathbf{z}}$ only affects the division of the surplus. The analysis of the first-best case confirms the result derived by Bell (1989) in the context of tenancy contracts, that, under costless monitoring, the insurer-agent and Nash bargaining solutions, assuming an a fine payment structure, are identical up to a side payment.

As, the more risk-averse is the client, the lower is $C E(\hat{\mathbf{n}})$, we obtain the result that, the more risk-averse is the client, the better off is the insurer. Note that this is not the standard bargaining theory result: the less risk-averse party, that is, the one with the less concave cardinal utility of wealth, has more bargaining power. In the present case, both the insurer and the client have cardinal utility linear in certainty-equivalent wealth. The result arises because, the more riskaverse is the client, the greater are the gains from insurance. As these gains are shared in proportion to bargaining power, the insurer is better off. On the other hand, because the client receives only part of the gains from insurance, a reduction in $C E(\hat{\mathbf{n}})$ leaves her strictly worse off whenever $\alpha<1$.

\section{Bargaining solution with hold-up problems}

In the second-best case with hold-up problems, the disagreement point, as before, is one in which the client chooses some $\tilde{\mathbf{z}}$, receiving $C E(\tilde{\mathbf{n}})$ and the insurer receives zero. The agreement point is one in which the output $\tilde{\mathbf{z}}$ is produced and the insurer offers full insurance, giving the client a nonstochastic payment $Y$ and receiving the profit

$$
P(\tilde{\mathbf{z}}, Y)=E[\tilde{\mathbf{z}}]-Y \text {. }
$$


70

This choice of agreement point reflects the fact that the agent must commit to an output vector before bargaining takes place. Thus, the bargaining problem is to choose $Y$ to maximise

$$
\hat{V}=((Y-C(\tilde{\mathbf{z}}))-C E(\tilde{\mathbf{n}}))^{\alpha} P(\tilde{\mathbf{z}}, Y)^{1-\alpha},
$$

which, as before, yields the solution condition

$$
\frac{((Y-C(\tilde{\mathbf{z}}))-C E(\tilde{\mathbf{n}}))}{P(\tilde{\mathbf{z}}, Y)}=\frac{\alpha}{(1-\alpha)} .
$$

Totally differentiating with respect to $\tilde{\mathbf{z}}$ and rearranging yields

$$
\begin{aligned}
(1-\alpha) \nabla_{\tilde{\mathbf{z}}}(Y-C-C E(\tilde{\mathbf{n}})) & =\alpha \nabla_{\tilde{\mathbf{z}}} P(\tilde{\mathbf{z}}, Y) \\
& =\alpha\left(\nabla_{\tilde{\mathbf{z}}} E[\tilde{\mathbf{z}}]-\nabla_{\tilde{\mathbf{z}}} Y\right),
\end{aligned}
$$

where $\nabla_{\tilde{\mathbf{z}}}$ denotes the gradient with respect to the subscripted vector. Hence,

$$
\nabla_{\tilde{\mathbf{z}}} Y-(1-\alpha) \nabla_{\tilde{\mathbf{z}}} C=(1-\alpha) \nabla_{\tilde{\mathbf{z}}} C E(\tilde{\mathbf{n}})+\alpha \nabla_{\tilde{\mathbf{z}}} E[\tilde{\mathbf{z}}] .
$$

In the case $\alpha=0$, we have

$$
\nabla_{\tilde{\mathbf{z}}}(Y-C)=\nabla_{\tilde{\mathbf{z}}} C E(\tilde{\mathbf{n}}),
$$

and the client will maximise $Y-C(\tilde{\mathbf{z}})=C E(\tilde{\mathbf{n}})$ by choosing $\tilde{\mathbf{z}}=\hat{\mathbf{z}}$. On the other hand, if $\alpha=1$,

$$
\nabla_{\tilde{\mathbf{z}}}(Y-C)=\nabla_{\tilde{\mathbf{z}}} E[\tilde{\mathbf{z}}]-\nabla_{\tilde{\mathbf{z}}} C,
$$

and the client will maximise $Y-C(\tilde{\mathbf{z}})=E[\tilde{\mathbf{z}}]-C(\tilde{\mathbf{z}})$ by choosing $\tilde{\mathbf{z}}=\mathbf{z}^{F B}$. More generally, the greater the value of $\alpha$, the greater the optimal value of $E[\tilde{\mathbf{z}}]-C(\tilde{\mathbf{z}})$ and therefore the greater the total surplus. Thus, if the client chooses the output vector $\mathbf{z}$ before the insurer can commit to a payment schedule, bargaining power matters not only to the division of the surplus but to the size of the surplus. It is straightforward to show, however, that an increase in $\alpha$ cannot make the insurer better off.

\section{Bargaining solution with asymmetric information}

In the asymmetric information case, the agreement point is one in which the output $\tilde{\mathbf{z}}$ is produced and the insurer offers an incentive compatible payment schedule y receiving profit

$$
P(\tilde{\mathbf{z}}, N)=E[\tilde{\mathbf{z}}]-E[\mathbf{y}(\mathbf{z}, N)],
$$


where $N$ is the client's certainty-equivalent net income

$$
N=u^{-1}(W(\mathbf{y}-C(\mathbf{z})))
$$

To simplify the analysis, we abstract from wealth effects by assuming that the client's preferences display constant absolute risk aversion. Then

$$
\frac{\partial P(\tilde{\mathbf{z}}, N)}{\partial N}=-\frac{\partial E[\mathbf{y}(\mathbf{z}, N)]}{\partial N}=-1 .
$$

The bargaining problem is to choose $N$ to maximise:

$$
\hat{V}=(N-C E(\tilde{\mathbf{n}}))^{\alpha} P(\tilde{\mathbf{z}}, N)^{1-\alpha},
$$

which, assuming constant absolute risk aversion, yields the solution condition

$$
\frac{(N-C E(\tilde{\mathbf{n}}))}{P(\tilde{\mathbf{z}}, u)}=\frac{\alpha}{(1-\alpha)}
$$

Totally differentiating with respect to $\tilde{\mathbf{z}}$ and rearranging yields

$$
\begin{aligned}
(1-\alpha) \nabla_{\tilde{\mathbf{z}}}(N-C E(\tilde{n})) & =\alpha \nabla_{\tilde{\mathbf{z}}} \frac{\partial P(\tilde{\mathbf{z}}, u)}{\partial \tilde{\mathbf{z}}} \\
& =\alpha \nabla_{\tilde{\mathbf{z}}}(E[\tilde{\mathbf{z}}]-E[\mathbf{y}(\mathbf{z})]) .
\end{aligned}
$$

In the case $\alpha=0$, we have

$$
\nabla_{\tilde{\mathbf{z}}}(N-C E(\tilde{\mathbf{n}}))=0,
$$

and the client will maximise $N$ by choosing $\tilde{\mathbf{z}}=\hat{\mathbf{z}}$. On the other hand, if $\alpha=1$, the client will maximise $N$ by choosing $\tilde{\mathbf{z}}=\mathbf{z}^{T B}$. Thus, once again, the greater the client's bargaining power, the greater the total surplus.

In the model of socially costly exploitation analysed by Chambers and Quiggin (2000), the presence of asymmetric information makes the agent (a tenant farmer) better off, by reducing the return to efforts by the principal (a landlord) aimed at reducing the tenant's reservation utility. By contrast, in the present case, asymmetric information never improves the welfare of either party, and makes both the insurer and the client strictly worse off whenever $0<\alpha<1$.

The results of the section above may be summarised by

Proposition 8 Assume constant absolute risk aversion, and consider bargaining in the presence of asymmetric information. An increase in the client's 
bargaining power increases the client's welfare, reduces the insurer's welfare, and increases total social surplus.

\section{Concluding comments}

This paper has explored the contracting behaviour of clients and insurers under conditions of asymmetric information and differential bargaining power. The main focus of attention has been the interaction between differential bargaining power and two potential sources of departure from the first-best. The first, which is applicable to a wide variety of contracting situations, is that clients anticipating the need to deal with a insurer with monopoly power (or, more generally, with substantial bargaining power) will undertake costly selfinsurance to improve the outside option that will form the basis of subsequent bargaining. The second is the problem of moral hazard, in which the client has private information about the state of nature.

The crucial result is that differential bargaining power will affect not only the distribution of surplus but the total surplus generated. When the client has private information, an increase in the bargaining power of the insurer will reduce total surplus. Although this result has been derived for the case of two states of nature, the logic is applicable more generally. A client who makes production decisions before bargaining with an insurer will commit excessive resources to risk reduction (relative to the unconstrained social optimum) to increase her utility in the disagreement outcome and thereby strengthen her bargaining position. However, in the case when there are only two possible outcomes, the client cannot trade off risk and expected return. Hence, in this special, but commonly modelled, case, the results derived above do not apply.

\section{References}

Arnott, R. and Stiglitz, J. (1988) 'The basic analytics of moral hazard', Scandinavian Journal of Economics 90(3): 383-413.

Arrow, K. (1963) 'Uncertainty and the welfare economics of medical care', American Economic Review 53(5): 941-973.

Baron, D.P. and Myerson, R.B. (1982) 'Regulating a monopolist with unknown costs', Econometrica 50(4): 911-930.

Bell, C. (1989) 'A comparison of principal-agent and bargaining solutions: The case of tenancy contracts', in P. Bardhan (ed.) The Economic Theory of Agrarian Institutions, Oxford: Clarendon Press.

Braverman, A. and Stiglitz, J. (1986) 'Landlords, tenants and technological innovations', Journal of Development Economics 23(2): 313-332.

Chambers, R.G. and Quiggin, J. (1996) 'Nonpoint pollution control as a multi-task principal-agent problem', Journal of Public Economics 59(1): 95-116. 
Chambers, R.G. and Quiggin, J. (2000) Uncertainty, Production, Choice and Agency: The StateContingent Approach, New York: Cambridge University Press.

Ehrlich, I. and Becker, G. (1972) 'Market insurance, self-insurance and self-protection', Journal of Political Economy 80: 623-648.

Ellsberg, D. (1961) 'Risk, ambiguity and the savage axioms', Quarterly Journal of Economics 75(4): 643-669.

Grossman, S. and Hart, O. (1983) 'An analysis of the principal-agent problem', Econometrica 51(1): 7-46.

Holmstrom, B. and Milgrom, P. (1987) 'Aggregation and linearity in the provision of intertemporal incentives', Econometrica 55(2): 303-328.

Holmstrom, B. and Roberts, J. (1998) 'The boundaries of the firm revisited', Journal of Economic Perspectives 12(4): 73-94.

Horowitz, J.K. and Lichtenberg, E. (1993) 'Insurance, moral hazard, and chemical use in agriculture', American Journal of Agricultural Economics 75: 926-935.

Kihlstrom, R.E. and Roth, A.E. (1982) 'Risk aversion and the negotiation of insurance contracts', Journal of Risk and Insurance 49(3): 372-387.

Klein, B., Crawford, R. and Alchian, A. (1978) 'Vertical integration, appropriable rents and the competitive contracting process', Journal of Law and Economics 21: 297-326.

Lewis, T. and Nickerson, D. (1989) 'Self-insurance against natural disasters', Journal of Environmental Economics and Management 16: 209-223.

Miranda, M.J. (1991) 'Area-yield crop insurance reconsidered', American Journal of Agricultural Economics 73: 233-242.

Newbery, D. (1977) 'Risk, sharecropping and uncertain labour markets', Review of Economic Studies 44(3): 585-594.

Quiggin, J. (2002) 'Risk and self-protection: A state-contingent view', Journal of Risk and Uncertainty 25(2): 133-145.

Quiggin, J. and Chambers, R.G. (1998) 'A state-contingent production approach to principalagent problems with an application to point-source pollution control', Journal of Public Economics 70(3): 441-472.

Racionero, M. and Quiggin, J. (2006) 'Fixed wages and bonuses in agency contracts: The case of a continuous state space', Journal of Public Economic Theory 8(5): 761-777.

Riddell, C. (1981) 'Bargaining under uncertainty', American Economic Review 71(4): 579-590.

Rogerson, W.P. (1992) 'Contractual solutions to the hold-up problem', The Review of Economic Studies 59(4): 777-793.

Roth, A.E. (1985) 'A note on risk aversion in a perfect equilibrium model of bargaining', Econometrica 53(1): 207-211.

Safra, Z., Zhou, L. and Zilcha, I. (1990) 'Risk aversion in the Nash bargaining problem with risky outcomes and risky disagreement points', Econometrica 58(4): 961-965.

Schlesinger, H. (1984) '2-Person insurance negotiation', Insurance Mathematics and Economics 3(3): $147-149$.

Viaene, S., Veugelers, R. and Dedene, G. (2002) 'Insurance bargaining under risk aversion', Economic Modelling 19(2): 245-259.

Williamson, O.E. (1983) 'Credible commitments: Using hostages to support exchange', The American Economic Review 73(4): 519-540.

Yellen, J.L. (1984) 'Efficiency wage models of unemployment', American Economic Review 74(2): 200-205. 